\title{
Diagnostic and Predictive Capacity of the Spanish Versions of the Opioid Risk Tool and the Screener and Opioid Assessment for Patients with Pain- Revised: A Preliminary Investigation in a Sample of People with Noncancer Chronic Pain
}

\author{
Rosa Esteve · Ángela Reyes-Pérez • Carmen Ramírez-Maestre (i) • \\ Andrea Gutiérrez-Extremera • Rocío Fuentes-Bravo • Rocío de la Vega • \\ Gema T. Ruíz-Párraga · Elena R. Serrano-Ibáñez • Alicia E. López-Martínez
}

Received: November 23, 2021 / Accepted: January 17, 2022 / Published online: February 7, 2022

(C) The Author(s) 2022

\begin{abstract}
Introduction: Accurate assessment of the risk of opioid abuse and misuse in people with noncancer chronic pain is crucial for their prevention. This study aimed to provide preliminary evidence of the diagnostic and predictive capacity of the Spanish versions of the Opioid Risk Tool (ORT) and the Screener and Opioid Assessment for Patients with Pain-Revised (SOAPP-R).
\end{abstract}

Methods: We used the Current Opioid Misuse Measure (COMM) as criterion measure to assess the capacity of each tool to identify patients misusing opioids at the time of the assessment. Eighteen months later, we used the COMM and the Drug Abuse Screening Test-10 (DAST-10) to assess their predictive capacity. In total, 147

R. Esteve · Á. Reyes-Pérez - C. Ramírez-Maestre $(\varangle) \cdot$ A. Gutiérrez-Extremera · R. Fuentes-Bravo · R. de la Vega · G. T. Ruíz-Párraga · E.

R. Serrano-Ibáñez · A. E. López-Martínez

Departamento de Personalidad, Evaluación y Tratamiento Psicológico, Facultad de Psicología y Logopedia, Universidad de Málaga, Campus de Teatinos, S/N, 29071 Málaga, Spain e-mail: cramirez@uma.es

R. Esteve · C. Ramírez-Maestre · R. de la Vega .

G. T. Ruíz-Párraga · E. R. Serrano-Ibáñez ·

A. E. López-Martínez

Instituto de Investigaciones Biomédicas de Málaga (IBIMA), Campus de Teatinos, S/N, 29071 Málaga, Spain people with noncancer chronic pain participated in the diagnostic study, and 42 in the predictive study.

Results: Receiver operating curve analysis showed that the SOAPP-R had an excellent capacity to identify participants who were misusing opioids at the time of assessment (area under the curve $[\mathrm{AUC}]=0.827$ ). The diagnostic capacity of the ORT was close to acceptable (AUC $=0.649-0.669)$, whereas its predictive capacity was poor (AUC $=0.522-0.554$ ). The predictive capacity of the SOAPP-R was close to acceptable regarding misuse (AUC = 0.672) and poor regarding abuse $(\mathrm{AUC}=0.423)$.

Conclusion: In the setting of Spanish-speaking communities, clinicians should be cautious when using these instruments to make decisions on opioid administration. Further research is needed on the diagnostic and predictive capacity of the Spanish versions of both instruments.

Keywords: Opioid abuse; Opioid misuse; Opioid Risk Tool; Screener and Opioid Assessment for Patients with Pain-Revised; Screening tools 


\section{Key Summary Points}

Why carry out this study?

Misuse and abuse of prescription opioids have increased.

Assessing the risk of opioid abuse and misuse is crucial for prevention.

No study is available on the validity of the Spanish versions of the Opioid Risk Tool (ORT) and the Screener and Opioid Assessment for Patients with PainRevised (SOAPP-R).

\section{What was learned from the study?}

The ORT showed close to acceptable diagnostic capacity and poor predictive capacity.

The SOAPP-R showed excellent diagnostic capacity, acceptable predictive capacity regarding misuse, and poor predictive capacity regarding abuse.

\section{INTRODUCTION}

Opioids are frequently prescribed for many chronic pain conditions. In the USA and some European Union countries, there has been a dramatic increase in the misuse and abuse of prescription opioids [1]. There is well-documented evidence on the adverse consequences of opioid abuse [2-6], including increased mortality due to unintentional overdosing and cardiorespiratory problems $[2,7,8]$. A recent report showed that the opioid crisis is increasing within Hispanic/Latino communities in the USA and that the language barrier hinders their access to adequate care [9]. In these communities, treatment alternatives are often scarce [10], and the monitoring of opioid misuse and abuse is typically not conducted [11]. One reason for the latter situation is that the appropriate instruments have not been adapted to Spanishspeaking populations.

There is general agreement on the necessity to assess the risk of opioid misuse and abuse in patients with noncancer chronic pain before initiating treatment [3]. Assessment before prescription can help tailor treatments to the patients' needs and characteristics and minimize the risk of opioid misuse and abuse [12]. Several measures have been created to assess the risk of developing aberrant behavior in the use of prescribed opioids for noncancer chronic pain conditions. There are Spanish translations of the Opioid Risk Tool (ORT) [13] and the Screener and Opioid Assessment for Patients with Pain-Revised (SOAPP-R) [14, 15]; however, there is no empirical evidence on their capacity to detect and predict opioid misuse or abuse.

Both instruments rely on the general assumption that the more aberrant the behavior of the individuals, the more likely the individuals are misusing or abusing opioids or will do so in the future $[13,14]$. Substance misuse was defined as using a drug in a way that differs from the prescription, and substance abuse was defined as use that is detrimental to the user or others or is illegal $[13,14]$.

The ORT included the following risk factors: a personal and family history of substance abuse; age between 16 and 45 years old; history of preadolescent sexual abuse; and certain psychological disorders [13]. The results on the capacity of the ORT to predict aberrant drugrelated behavior are mixed, ranging from acceptable to no discrimination [16-22]. Several authors have suggested that some studies had follow-up periods shorter than 1 year, which could explain these inconsistent results [18], given that the duration of the follow-up period should be at least 1 year. This requirement was fulfilled in the initial validation study of the instrument [13]. Another factor underlying the aforementioned contradictory results could be social desirability bias fostered by the explicit nature of the items of the ORT. Thus, some patients can easily manipulate their answers to appear to be at lower risk than is actually the case $[21,22]$. Indeed, a study demonstrated that the way in which the ORT was administered made a significant difference to the results because aberrant drug-taking was better predicted by the clinician-completed ORT than by 
the patient-completed ORT [21]. The authors suggested that the discrepancies were mainly due to comprehension issues [21].

To try to remedy this shortcoming, the SOAPP included subtle items that are not obviously related to aberrant drug behavior (e.g., feeling bored, impatient, angry). A panel of pain and addiction experts identified eight conceptual clusters of risk factors for potential problems with opioids in people considered for opioid therapy: antisocial behavior/history, substance abuse history, medication-related behavior, doctor-patient relationship factors, psychiatric history, emotional attachment to pain medications, personal care, lifestyle issues, and psychosocial problems. The SOAPP comprised items representing each of the eight identified concepts [23]. The SOAPP-R was the outcome of later refinements of this initial conceptual framework and subsequent empirical studies to select the items that were the best predictors of medication misuse [14]. Results on the diagnostic and predictive capacity of the SOAPP-R are inconsistent [16, 18-20, 22, 24].

\section{METHODS}

\section{Study Aim}

The aim of the study was to provide preliminary evidence of the diagnostic and predictive capacity of the Spanish translations of the ORT and the SOAPP-R in a sample of people with chronic pain, given that there is no empirical evidence on their capacity to detect and predict opioid misuse or abuse. To overcome the shortcomings of the aforementioned research, in this study, clinicians orally administered all the instruments to control for social desirability bias and avoid comprehension issues. We also included a follow-up period of more than 1 year (18 months).

\section{Study Design}

We used the Current Opioid Misuse Measure (COMM) [25] as a criterion measure to test the capacity of the ORT and the SOAPP-R to identify patients who were misusing opioids at the time of the assessment. Eighteen months later, we used the COMM [25] and the Drug Abuse Screening Test (DAST-10) $[26,27]$ to test their predictive capacity in a subsample of patients.

\section{Study Setting}

Participants were recruited through two local associations of people with fibromyalgia and two pain units.

\section{Inclusion Criteria}

The inclusion criteria were as follows: at the time of the study, participants were experiencing pain and had been experiencing pain for at least the last 3 months; they were over 18 years old; they were not being treated for a malignancy, terminal illness, or psychiatric disorder; they had been under opioid treatment for more than 90 days [28]; and they were able to understand Spanish, the instructions, and the questionnaires.

\section{Participants}

We tested the capacity of the ORT and the SOAPP-R to classify patients according to opioid misuse using a convenience sample of 147 individuals with noncancer chronic pain; 18 months later, 42 of them completed the second assessment. Tables 1, 2, and 3 show the descriptive statistics of the demographic and clinical variables. The daily dose of opioids was calculated and converted to oral morphine milligram equivalents (MME) using recommended conversion factors [29]. The median MME per day was "moderate" (51-89 MME/d) [29] (Table 2) in the initial sample and "low" (Table 3) in the subsample. Opioids and benzodiazepines were simultaneously consumed by $37.41 \%$ of participants in the initial sample and $26.19 \%$ in the subsample. 
Table 1 Description of the participants

\begin{tabular}{|c|c|c|}
\hline Variables & $\begin{array}{l}\text { Initial } \\
\text { sample } \\
(n=147) \\
n(\%)\end{array}$ & $\begin{array}{l}\text { Subsample } \\
(n=42) \\
n(\%)\end{array}$ \\
\hline \multicolumn{3}{|l|}{ Sex } \\
\hline Female & $114(77.55)$ & $35(83.33)$ \\
\hline Male & $33(22.45)$ & $7(16.67)$ \\
\hline \multicolumn{3}{|l|}{ Marital status } \\
\hline Single & $7(4.80)$ & $2(4.80)$ \\
\hline Married/cohabiting & $115(78.20)$ & $32(76.19)$ \\
\hline Divorced/separated & $15(10.20)$ & $4(9.50)$ \\
\hline Widowed & $10(6.80)$ & $4(9.50)$ \\
\hline \multicolumn{3}{|l|}{ Education } \\
\hline Ability to read and write & $10(6.80)$ & $2(4.80)$ \\
\hline Primary school & $77(52.40)$ & $25(59.50)$ \\
\hline High school & $47(32)$ & $10(23.80)$ \\
\hline University education & $13(8.80)$ & $5(11.90)$ \\
\hline \multicolumn{3}{|l|}{ Employment status } \\
\hline Employed & $29(19.70)$ & $4(9.50)$ \\
\hline Homemaker & $42(28.60)$ & $16(38.10)$ \\
\hline Retired & $61(41.50)$ & $15(35.70)$ \\
\hline Unemployed & $15(10.20)$ & $7(16.67)$ \\
\hline \multicolumn{3}{|l|}{ Pain diagnosis } \\
\hline Primary pain syndromes & $65(44.2)$ & $23(54.76)$ \\
\hline \multicolumn{3}{|l|}{ Secondary pain syndromes } \\
\hline Musculoskeletal & $66(44.9)$ & $16(38.10)$ \\
\hline Neuropathic & $6(4.10)$ & $2(4.76)$ \\
\hline Postsurgical/posttraumatic & $5(3.40)$ & $1(2.38)$ \\
\hline Orofacial & $1(.70)$ & - \\
\hline Visceral & $4(2.70)$ & - \\
\hline \multicolumn{3}{|l|}{ Medication $^{\mathrm{a}}$} \\
\hline Nonopioid analgesics & $46(31.08)$ & $14(33.33)$ \\
\hline $\begin{array}{l}\text { Nonsteroidal anti- } \\
\text { inflammatory drugs }\end{array}$ & $89(60.81)$ & $34(80.95)$ \\
\hline Anticonvulsants & $68(45.95)$ & $11(26.19)$ \\
\hline
\end{tabular}

Table 1 continued

\begin{tabular}{lll}
\hline Variables & $\begin{array}{l}\text { Initial } \\
\text { sample } \\
\left(\begin{array}{l}\boldsymbol{n}=147) \\
\boldsymbol{n}(\%)\end{array}\right.\end{array}$ & $\begin{array}{l}\text { Subsample } \\
(\boldsymbol{n}=\mathbf{4 2})\end{array}$ \\
& $\mathbf{n}(\%)$ \\
\hline Benzodiazepines & $64(43.24)$ & $14(33.33)$ \\
Antidepressants & $54(36.49)$ & $8(19.05)$ \\
Other & $7(4.73)$ & $3(7.14)$ \\
\hline
\end{tabular}

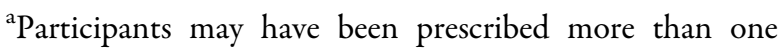
medication

\section{Data Collection Tools}

\section{Pain Index}

Participants were asked to rate their least, average, and worst pain during the past 2 weeks and their current pain on an 11-point Likert scale. The mean of these ratings was calculated to obtain a composite pain intensity score [30].

\section{Opioid Risk Tool (ORT)}

The ORT [13] is a 10-item instrument used to predict the risk of engaging in aberrant drugrelated behavior in patients with chronic pain receiving prescribed opioid therapy. Respondents are questioned on each risk factor and their answers are weighted from 1 to 5 depending on the item. Previous studies on the capacity of the ORT to predict aberrant drugrelated behaviors reported area under the curve (AUC) values that ranged from 0.358 to 0.735 , sensitivity values that ranged from 0.20 to 0.75 , and specificities that ranged from 0.54 to 0.88 [16-22]. One study [17] found that, after excluding the item related to a history of preadolescent sexual abuse, the unweighted version of the ORT was superior to the original ORT in detecting patients with and without opioid use disorder. Thus, we computed four scores: two weighted scores (one with and one without the item related to a history of preadolescent sexual abuse) and two unweighted scores (one with and one without this item). We used the Spanish translation of the questionnaire (Webster \& Webster, https://www. lynnwebstermd.com/opioid-risk-tool/). 
Table 2 Means, standard deviations, and correlations between variables, $n=147$

\begin{tabular}{|c|c|c|c|c|c|c|c|c|c|c|c|}
\hline Variables & $M(\mathrm{SD})$ & 1 & 2 & 3 & 4 & 5 & 6 & 7 & 8 & 9 & 10 \\
\hline $\begin{array}{l}\text { 1. ORT weighted } \\
\text { scores including } \\
\text { item related to } \\
\text { sexual abuse }\end{array}$ & $\begin{array}{l}2.47 \\
\quad(2.79)\end{array}$ & 1 & $0.96^{* * *}$ & $0.91^{* * *}$ & $0.86^{* * *}$ & $0.28^{* * *}$ & $0.28^{* * *}$ & $-0.28^{* *}$ & -0.15 & -0.09 & 0.02 \\
\hline $\begin{array}{l}\text { 2. ORT weighted } \\
\text { scores excluding } \\
\text { item related to } \\
\text { sexual abuse }\end{array}$ & $\begin{array}{l}2.22 \\
\quad(2.49)\end{array}$ & & 1 & $0.87^{* * *}$ & $0.89^{* * *}$ & $0.28^{* * *}$ & $0.22^{* *}$ & $-0.25^{* *}$ & -0.12 & -0.10 & 0.03 \\
\hline $\begin{array}{l}\text { 3. ORT unweighted } \\
\text { scores including } \\
\text { item related to } \\
\text { sexual abuse }\end{array}$ & $\begin{array}{l}1.51 \\
\quad(1.16)\end{array}$ & & & 1 & $0.97^{* * *}$ & $0.37^{* * *}$ & $0.28^{* * *}$ & $-0.33^{* * *}$ & -0.09 & -0.09 & 0.04 \\
\hline $\begin{array}{l}\text { 4. ORT unweighted } \\
\text { scores excluding } \\
\text { item related to } \\
\text { sexual abuse }\end{array}$ & $1.43(1.07)$ & & & & 1 & $0.37^{* * *}$ & $0.29^{* * *}$ & $-0.31^{* * *}$ & -0.07 & -0.10 & 0.05 \\
\hline 5. SOAPP-R & $\begin{array}{r}31.34 \\
\quad(11.69)\end{array}$ & & & & & 1 & $0.57^{* * *}$ & $-0.27^{* *}$ & $0.24^{* *}$ & -0.13 & -0.02 \\
\hline 6. COMM & $\begin{array}{l}15.70 \\
\quad(8.38)\end{array}$ & & & & & & 1 & $-0.16^{*}$ & $0.18^{*}$ & 0.03 & -0.03 \\
\hline 7. Age & $\begin{array}{r}60.69 \\
\quad(9.98)\end{array}$ & & & & & & & 1 & 0.09 & $0.27^{* *}$ & -0.07 \\
\hline 8. Pain intensity & $\begin{array}{l}7.40 \\
\quad(1.39)\end{array}$ & & & & & & & & 1 & -0.08 & -0.03 \\
\hline 9. Pain duration & $\begin{array}{l}17.06 \\
(12.99)\end{array}$ & & & & & & & & & 1 & 0.04 \\
\hline 10. Oral MME/d & $\begin{array}{l}54.46 \\
\quad(86.09)\end{array}$ & & & & & & & & & & 1 \\
\hline
\end{tabular}

$M$ mean, $S D$ standard deviation, $M M E$ morphine milligram equivalents, ORT Opioid Risk Tool, SOAPP-R Screener and Opioid Assessment for Patients with Pain-Revised, COMM Current Opioid Misuse Measure

${ }^{*} p<0.05 ;{ }^{* *} p<0.01 ;{ }^{* * *} p<0.001$

\section{Screener and Opioid Assessment for Patients with Pain-Revised (SOAPP-R)}

The SOAPP-R is a 24-item questionnaire used to identify a patient's risk of abnormal drug-related behavior [14]. It is scored on a scale from 0 to 4. Previous studies have obtained a great range of values regarding the sensitivity and specificity of the SOAPP-R, ranging from 0.91 to
0.54 and from 0.39 to 0.71 , respectively $[16,18-20,22,24]$. We used the Spanish translation of the questionnaire published by its authors [15].

Current Opioid Misuse Measure (COMM)

This instrument is used to monitor chronic pain patients receiving opioid therapy who may be 
Table 3 Means, standard deviations, and correlations between variables, $n=42$

\begin{tabular}{|c|c|c|c|c|c|c|c|c|c|c|c|c|}
\hline Variables & $M(\mathrm{SD})$ & 1 & 2 & 3 & 4 & 5 & 6 & 7 & 8 & 9 & 10 & 11 \\
\hline $\begin{array}{l}\text { 1.ORT weighted } \\
\text { scores } \\
\text { including item } \\
\text { related to } \\
\text { sexual abuse }\end{array}$ & $\begin{array}{l}1.36 \\
\quad(1.25)\end{array}$ & 1 & $0.86^{* * *}$ & $0.91^{* * *}$ & $0.81^{* * *}$ & $0.46^{* *}$ & 0.08 & 0.12 & -0.23 & 0.12 & -0.24 & 0.17 \\
\hline $\begin{array}{l}\text { 2. ORT } \\
\text { weighted } \\
\text { scores } \\
\text { excluding item } \\
\text { related to } \\
\text { sexual abuse }\end{array}$ & $\begin{array}{l}1.21 \\
\quad(1.02)\end{array}$ & & 1 & $0.87^{* * *}$ & $0.91^{* * *}$ & $0.51^{* * *}$ & 0.20 & 0.25 & -0.03 & 0.22 & -0.23 & 0.29 \\
\hline $\begin{array}{l}\text { 3. ORT } \\
\text { unweighted } \\
\text { scores } \\
\text { including item } \\
\text { related to } \\
\text { sexual abuse }\end{array}$ & $\begin{array}{l}1.14 \\
\quad(0.81)\end{array}$ & & & 1 & $0.97^{* * *}$ & $0.51^{* * *}$ & 0.05 & 0.10 & -0.12 & 0.17 & -0.26 & 0.14 \\
\hline $\begin{array}{l}\text { 4. ORT } \\
\text { unweighted } \\
\text { scores } \\
\text { excluding item } \\
\text { related to } \\
\text { sexual abuse }\end{array}$ & $\begin{array}{l}1.09 \\
(0.76)\end{array}$ & & & & 1 & $0.52^{* * *}$ & 0.10 & 0.16 & -0.01 & 0.22 & -0.25 & 0.18 \\
\hline 5. SOAPP-R & $\begin{array}{l}32.21 \\
\quad(9.61)\end{array}$ & & & & & 1 & 0.17 & $0.34^{*}$ & -0.05 & $0.39^{* *}$ & -0.21 & 0.04 \\
\hline $\begin{array}{l}\text { 6. COMM } \\
\text { (follow-up) }\end{array}$ & $\begin{array}{r}13.86 \\
(8.27)\end{array}$ & & & & & & 1 & $0.51^{* * *}$ & -0.16 & 0.15 & 0.21 & 0.00 \\
\hline $\begin{array}{l}\text { 7. DAST } \\
\text { (follow-up) }\end{array}$ & $\begin{array}{l}1.90 \\
(1.90)\end{array}$ & & & & & & & 1 & -0.13 & 0.07 & -0.04 & 0.26 \\
\hline 8. Age & $\begin{array}{l}60.81 \\
\quad(8.21)\end{array}$ & & & & & & & & 1 & -0.04 & 0.20 & -0.08 \\
\hline 9. Pain intensity & $\begin{array}{l}7.25 \\
(1.27)\end{array}$ & & & & & & & & & 1 & -0.01 & 0.05 \\
\hline $\begin{array}{l}\text { 10. Pain } \\
\text { duration }\end{array}$ & $\begin{array}{l}15.87 \\
\quad(13.11)\end{array}$ & & & & & & & & & & 1 & -0.02 \\
\hline
\end{tabular}


Table 3 continued

\begin{tabular}{lcccccccccccc}
\hline Variables & $\boldsymbol{M}(\mathbf{S D})$ & $\mathbf{1}$ & $\mathbf{2}$ & $\mathbf{3}$ & $\mathbf{4}$ & $\mathbf{5}$ & $\mathbf{6}$ & $\mathbf{7}$ & $\mathbf{8}$ & $\mathbf{9}$ & $\mathbf{1 0}$ & $\mathbf{1 1}$ \\
\hline $\begin{array}{c}\text { 11. Oral MME/ } \\
\text { d (follow-up) }\end{array}$ & $\begin{array}{c}50.21 \\
(70.25)\end{array}$ & & & & & & & & & & & 1 \\
\hline
\end{tabular}

$M$ mean, $S D$ standard deviation, $M M E$ morphine milligram equivalents, ORT Opioid Risk Tool, SOAPP-R Screener and Opioid Assessment for Patients with Pain-Revised, COMM Current Opioid Misuse Measure, DAST-10 Drug Abuse Screening Test

${ }^{*} p<0.05 ;{ }^{* *} p<0.01 ;{ }^{* * *} p<0.001$

manifesting behavior suggestive of substance abuse $[25,31]$. The COMM comprises 17 items rated on a scale from zero to four. A total score of nine or more indicates positive opioid misuse. The Spanish adaptation showed high internal consistency $(\alpha=0.80)$, test-retest reliability (ICC 0.97 ; 95\% CI 0.94-0.99), and adequate internal, criterion, and convergent validity [32].

\section{Drug Abuse Screening Test (DAST-10)}

The DAST-10 is designed to identify problems related to drug abuse during the past year [26]. Using DSM-IV TR as a criterion measure and a cutoff point of $\geq 3$, the Spanish version has been shown to correctly classify $95.36 \%$ of participants [27].

\section{Data Collection Procedure}

Demographic and clinical data were obtained via semi-structured interviews with a psychologist who also administered the ORT, SOAPP-R, and COMM. Data were collected between October 2018 and January 2020. In December 2020, participants in the initial sample who had been assessed 18 months before were contacted and assessed again. At this time point, they were interviewed regarding medication intake and pain intensity, and the COMM and DAST-10 were administered.

\section{Ethical Issues}

All the procedures were conducted in accordance with the Helsinki Declaration of 1964 and its later amendments. The project of which this study is part received ethical clearance from the Institutional Ethics Review Board (reference: CEUMA 66-2019-H). Participants provided a signed informed consent and confidentiality was maintained at every stage of the study.

\section{Statistical Analyses}

Data were analyzed using SPSS 22 (Statistical Package for the Social Sciences; Chicago, USA). We calculated means, standard deviations, and Pearson correlations. We also performed $t$ tests to determine if there were significant associations between the sex of the participants and the mean total scores on the ORT, SOAPP-R, COMM, and DAST-10. The guidelines proposed by Cohen [33] were used to assess the size of correlations. Receiver operating characteristic (ROC) curve analysis was used to calculate the AUC (c-statistic) [34, 35]. Values of $c$ equal to 0.50 indicate no discrimination, values between 0.70 and 0.80 are considered acceptable, values greater than 0.80 but less than 0.90 indicate excellent discrimination, and values greater than 0.90 indicate outstanding discrimination $[34,35]$. ROC analysis also provides estimations of sensitivity and specificity. Sensitivity is the proportion of true positives (i.e., people abusing or misusing opioids) that are correctly identified, and specificity is the proportion of true negatives (i.e., people who are not abusing or misusing opioids) that are correctly identified. We used MedCalc v.9.5.2.0 software to determine the optimal cutoff points and the sample size. 
Table 4 ROC analysis

\begin{tabular}{lll}
\hline Instrument & AUC & 95\% CI \\
\hline Criterion: COMM $(n=147)$ & & \\
ORT weighted scores including item related to sexual abuse & $0.658^{*}$ & $0.542-0.773$ \\
ORT weighted scores excluding item related to sexual abuse & $0.649^{*}$ & $0.553-0.766$ \\
ORT unweighted scores including item related to sexual abuse & $0.665^{* *}$ & $0.552-0.779$ \\
ORT unweighted scores excluding item related to sexual abuse & $0.669^{* *}$ & $0.556-0.782$ \\
SOAPP-R & $0.827^{* * *}$ & $0.737-0.918$ \\
Criterion: COMM $(n=42)$ & & \\
ORT weighted scores including item related to sexual abuse & 0.526 & $0.334-0.717$ \\
ORT weighted scores excluding item related to sexual abuse & 0.554 & $0.366-0.741$ \\
ORT unweighted scores including item related to sexual abuse & 0.522 & $0.329-0.714$ \\
ORT unweighted scores excluding item related to sexual abuse & 0.543 & $0.353-0.734$ \\
SOAPP-R & 0.672 & $0.510-0.835$ \\
Criterion: DAST $(n=42)$ & & \\
ORT weighted scores including item related to sexual abuse & 0.541 & $0.323-0.758$ \\
ORT weighted scores excluding item related to sexual abuse & 0.547 & $0.336-0.757$ \\
ORT unweighted scores including item related to sexual abuse & 0.533 & $0.311-0.754$ \\
ORT unweighted scores excluding item related to sexual abuse & 0.538 & $0.322-0.753$ \\
SOAPP-R & 0.423 & $0.230-0.616$ \\
\hline Area
\end{tabular}

${ }^{\mathrm{a}}$ Area under the curve of the ORT or SOAPP-R

$A U C$ area under the curve; 95\% CI 95\% confidence interval, ORT Opioid Risk Tool, SOAPP-R Screener and Opioid Assessment for Patients with Pain-Revised, COMM Current Opioid Misuse Measure, DAST-10 Drug Abuse Screening Test

${ }^{*} p<0.05 ;{ }^{* *} p<0.01 ;{ }^{* * *} p<0.001$

\section{Sample Size Calculation}

MedCalc v.9.5.2.0 indicated that, for an AUC of 0.80 , a sample size of 30 participants would indicate that the analysis had high power $(0.80)$ to reject the null hypothesis (value of $c=0.50$, meaning no discrimination) at the 0.05 significance level. For an AUC of 0.70, a sample size of 72 participants would indicate that the analysis had high power (0.80) to reject the null hypothesis (value of $c=0.50$, meaning no discrimination) at the 0.05 significance level.

\section{RESULTS}

\section{Descriptive Analyses}

No associations were found between the sex of the participants and the mean total scores on the ORT, SOAPP-R, COMM, and DAST-10. Tables 2 and 3 show the means and standard deviations of the continuous variables and their correlations. As expected, strong correlations were found between the four total scores of the ORT. In the initial sample, weak to moderate positive correlations were found between scores on the ORT and the SOAPP-R. In the follow-up 
sample, moderate to strong positive correlations were found between scores on the ORT and the SOAPP-R.

In the initial sample, a strong positive correlation was found between scores on the COMM and the SOAPP-R, whereas a weak to moderate positive correlation was found between scores on the COMM and the ORT.

In the follow-up sample, weak correlations were found between scores on the ORT, the SOAPP-R and the COMM. A weak correlation was found between scores on the DAST-10 and the ORT, and a moderate positive correlation was found between scores on the DAST-10 and the SOAPP-R. A strong correlation was found between scores on the DAST-10 and the COMM. In both the initial and follow-up samples, a negative correlation was found between the age of the participants and all measures of risk, misuse, and abuse.

\section{Capacity of the ORT and the SOAPP-R to Identify Patients Misusing Opioids Using the COMM as the Criterion Measure}

According to the COMM cutoff score, 119 participants $(80.95 \%)$ in the initial sample were misusing opioids. The ROC analysis showed that the SOAPP-R had an excellent capacity to identify participants who were misusing opioids at the time of assessment (Table 4). Regarding the ORT, although the AUC values were statistically significant, they can only be considered "almost acceptable" [34, 35]. Tables 5 and 6 show the sensitivity and specificity values for scores on the ORT and the SOAPP-R, respectively, and Fig. 1 shows the associated ROC curve. In the case of the ORT, we present the ROC curve and the coordinates for the unweighted scoring excluding the item related to sexual abuse because it is the one with the highest AUC value. Table 5 shows that for a score equal to or greater than 0.50 , sensitivity was high (0.874) and specificity was low (0.357), whereas for a score equal to or greater than 1.50 , sensitivity was considerably lower (0.454) and specificity was higher (0.786). Given that the ORT is a screening tool, we chose a cutoff point of 1 to reduce the possibility of failing to identify high-risk patients. For a score of 1 , the proportion of people misusing opioids who were correctly identified was $87.39 \%$ and the proportion of people not misusing opioids who were correctly identified was $35.71 \%$. The positive predictive value was $85.25 \%$, the negative predictive value was $40 \%$, and the positive likelihood ratio was 1.36 .

Regarding the SOAPP-R, Table 6 shows that values between 21 and 24 showed high sensitivity values and moderate specificity values. Thus, a cutoff point of 21 or 22 would be appropriate, as shown by the sensitivity values, specificity values, positive predictive values, negative predictive values, positive likelihood ratios, and negative likelihood ratios for these scores (Table 7).

\section{Capacity of the ORT and the SOAPP-R to Predict Opioid Misuse (COMM) and Abuse (DAST-10)}

According to the COMM cutoff score, 28 participants (59.57\%) in the follow-up sample were misusing opioids, and according to the DAST-10

Table 5 Sensitivity and specificity values of the total scores on the ORT (unweighted scores excluding the item related to sexual abuse) for detecting opioid misuse (criterion: COMM), $n=147$

\begin{tabular}{rlll}
\hline Instrument & $\begin{array}{l}\text { ORT detection } \\
\text { score is positive } \\
\text { if equal to or } \\
\text { greater than }\end{array}$ & Sensitivity & Specificity \\
\hline ORT & -1.0000 & 1.000 & 0.000 \\
0.5000 & 0.874 & 0.357 \\
1.5000 & 0.454 & 0.786 \\
2.5000 & 0.143 & 0.929 \\
3.5000 & 0.050 & 1.000 \\
4.5000 & 0.017 & 1.000 \\
5.5000 & 0.008 & 1.000 \\
7.0000 & 0.000 & 1.000 \\
\hline
\end{tabular}

ORT Opioid Risk Tool, COMM Current Opioid Misuse Measure 
Table 6 Sensitivity and specificity values of the total scores of the SOAPP-R for detecting opioid misuse (criterion (OMM), $n=147$

\begin{tabular}{|c|c|c|c|}
\hline Instrument & $\begin{array}{l}\text { SOAPP-R } \\
\text { detection score } \\
\text { is positive if } \\
\text { equal to or } \\
\text { greater than }\end{array}$ & Sensitivity & Specificity \\
\hline \multirow[t]{27}{*}{ SOAPP-R } & 2.0000 & 1.000 & 0.000 \\
\hline & 3.5000 & 1.000 & 0.036 \\
\hline & 6.0000 & 1.000 & 0.071 \\
\hline & 8.5000 & 1.000 & 0.143 \\
\hline & 9.5000 & 1.000 & 0.179 \\
\hline & 10.5000 & 0.992 & 0.179 \\
\hline & 11.5000 & 0.983 & 0.214 \\
\hline & 13.0000 & 0.983 & 0.286 \\
\hline & 14.5000 & 0.975 & 0.321 \\
\hline & 15.5000 & 0.958 & 0.393 \\
\hline & 16.5000 & 0.958 & 0.429 \\
\hline & 17.5000 & 0.958 & 0.464 \\
\hline & 18.5000 & 0.924 & 0.464 \\
\hline & 19.5000 & 0.908 & 0.500 \\
\hline & 21.0000 & 0.899 & 0.607 \\
\hline & 22.5000 & 0.874 & 0.607 \\
\hline & 23.5000 & 0.815 & 0.643 \\
\hline & 24.5000 & 0.815 & 0.679 \\
\hline & 25.5000 & 0.773 & 0.714 \\
\hline & 26.5000 & 0.756 & 0.821 \\
\hline & 27.5000 & 0.714 & 0.821 \\
\hline & 28.5000 & 0.689 & 0.821 \\
\hline & 29.5000 & 0.630 & 0.821 \\
\hline & 30.5000 & 0.613 & 0.821 \\
\hline & 31.5000 & 0.605 & 0.821 \\
\hline & 32.5000 & 0.546 & 0.821 \\
\hline & 33.5000 & 0.496 & 0.857 \\
\hline
\end{tabular}

Table 6 continued

\begin{tabular}{|c|c|c|c|}
\hline Instrument & $\begin{array}{l}\text { SOAPP-R } \\
\text { detection score } \\
\text { is positive if } \\
\text { equal to or } \\
\text { greater than }\end{array}$ & Sensitivity & Specificity \\
\hline & 34.5000 & 0.471 & 0.964 \\
\hline & 35.5000 & 0.462 & 0.964 \\
\hline & 36.5000 & 0.420 & 0.964 \\
\hline & 37.5000 & 0.395 & 0.964 \\
\hline & 38.5000 & 0.361 & 0.964 \\
\hline & 39.5000 & 0.336 & 0.964 \\
\hline & 40.5000 & 0.303 & 0.964 \\
\hline & 41.5000 & 0.269 & 0.964 \\
\hline & 42.5000 & 0.244 & 0.964 \\
\hline & 43.5000 & 0.210 & 0.964 \\
\hline & 44.5000 & 0.185 & 0.964 \\
\hline & 45.5000 & 0.151 & 0.964 \\
\hline & 46.5000 & 0.109 & 0.964 \\
\hline & 47.5000 & 0.101 & 0.964 \\
\hline & 48.5000 & 0.084 & 0.964 \\
\hline & 49.5000 & 0.059 & 0.964 \\
\hline & 50.5000 & 0.050 & 0.964 \\
\hline & 51.5000 & 0.034 & 1.000 \\
\hline & 52.5000 & 0.017 & 1.000 \\
\hline & 53.5000 & 0.008 & 1.000 \\
\hline & 55.0000 & 0.000 & 1.000 \\
\hline
\end{tabular}

SOAPP-R Screener and Opioid Assessment for Patients with Pain-Revised, COMM Current Opioid Misuse Measure

cutoff score of 3, 32 participants (76.19\%) in the follow-up sample were abusing opioids.

None of the AUC values were significant (Table 4, Figs. 2, 3). Regarding the ORT, the AUC values indicated poor predictive capacity. In the case of the SOAPP-R, the AUC value was "almost acceptable" in relation to the COMM cutoff score and poor regarding the DAST-10 


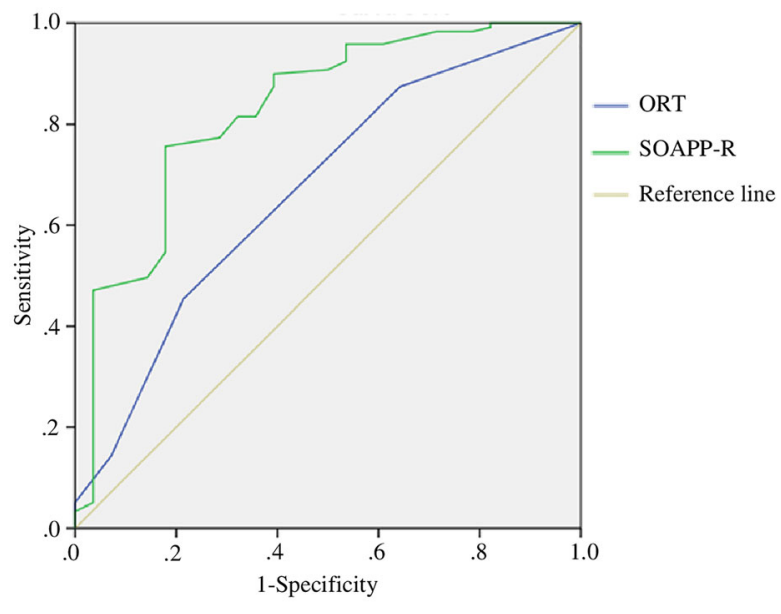

Fig. 1 Receiver operating characteristic curves comparing ORT (unweighted scores excluding the item related to sexual abuse) and SOAPP-R to detect opioid misuse (criterion measure: COMM). $n=147$. ORT Opioid Risk Tool, SOAPP-R Screener and Opioid Assessment for Patients with Pain-Revised, COMM Current Opioid Misuse Measure

cutoff score. Tables 8 and 9 show the sensitivity and specificity values of the total scores of the ORT and the SOAPP-R for predicting opioid misuse (COMM) and abuse (DAST-10). In the case of the ORT, we used the weighted score excluding the item related to sexual abuse because it was the score with the highest AUC value.
In the case of the ORT, a cutoff point of 1 should be used with the COMM and DAST-10 because there is a marked decrease in sensitivity at higher values (Tables 8, 9). Regarding the SOAPP-R, a cutoff point of 21 should be used with the COMM (Table 8). Using this cutoff point, sensitivity was $85.71 \%$, specificity was $21.43 \%$, the positive predictive value was $68.57 \%$, the negative predictive value was $42.86 \%$, the positive likelihood ratio was 1.09 , and the negative likelihood ratio was 0.67. In relation to the DAST-10, the cutoff of the SOAPP-R was not computed because the AUC value was very small $(0.423)$ (Table 4$)$.

\section{DISCUSSION}

Firstly, it is noteworthy that the results of the COMM showed that large percentages of the participants in the initial and follow-up samples (80.98\% and $59.57 \%$, respectively) were misusing opioids. The results of the DAST showed that $76.19 \%$ of the participants in the follow-up sample were abusing opioids. These results highlight the extent of the phenomenon and agree with those of previous research showing that there has been a dramatic increase in the misuse and abuse of prescription opioids [1].

This study showed that $37.41 \%$ of participants in the initial sample and $26.19 \%$ of those in the follow-up sample received simultaneous

Table 7 Assessment of the SOAPP-R cutoff points

\begin{tabular}{lllllll}
\hline $\begin{array}{l}\text { SOAPP-R } \\
\text { cutoff score }\end{array}$ & $\begin{array}{l}\text { Sensitivity } \\
(\%)\end{array}$ & $\begin{array}{l}\text { Specificity } \\
(\%)\end{array}$ & $\begin{array}{l}\text { Positive } \\
\text { predictive value } \\
(\%)\end{array}$ & $\begin{array}{l}\text { Negative } \\
\text { predictive value } \\
(\%)\end{array}$ & $\begin{array}{l}\text { Positive } \\
\text { likelihood } \\
\text { ratio }\end{array}$ & $\begin{array}{l}\text { Negative } \\
\text { likelihood ratio }\end{array}$ \\
\hline $\begin{array}{l}\text { Score of } 21 \text { or } \\
\text { above }\end{array}$ & 89.92 & 60.71 & 90.68 & 58.62 & 2.29 & 0.17 \\
$\begin{array}{l}\text { Score of } 22 \text { or } \\
\text { above }\end{array}$ & 89.92 & 60.71 & 90.68 & 58.62 & 2.29 & 0.17 \\
$\begin{array}{c}\text { Score of } 23 \text { or } \\
\text { above }\end{array}$ & 87.39 & 60.71 & 90.43 & 53.12 & 2.22 & 0.21 \\
$\begin{array}{l}\text { Score of } 24 \text { of } \\
\text { above }\end{array}$ & 81.51 & 64.29 & 90.65 & 45 & 2.28 & 0.29 \\
\hline
\end{tabular}

SOAPP-R Screener and Opioid Assessment for Patients with Pain-Revised 


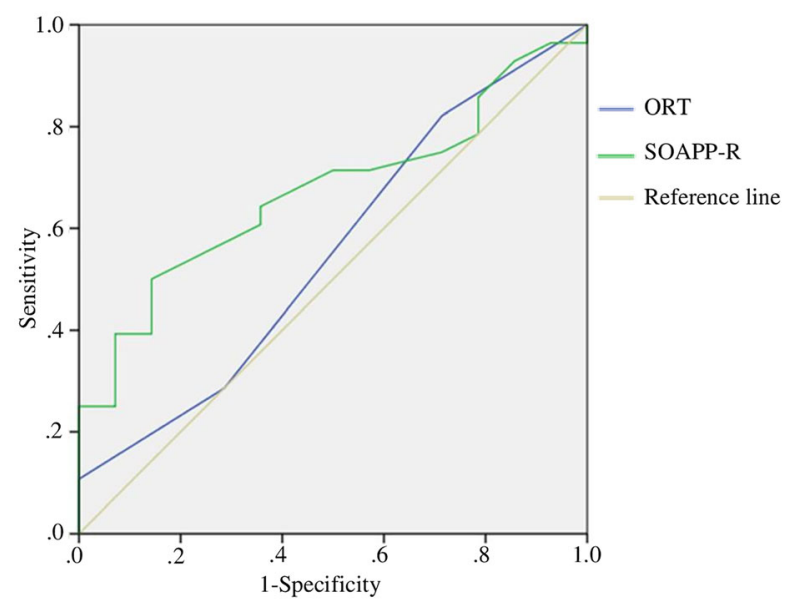

Fig. 2 Receiver operating characteristic curves comparing ORT (weighted score excluding item related to sexual abuse) and SOAPP-R to predict opioid misuse (criterion measure: COMM). $n=42$. ORT Opioid Risk Tool, SOAPP-R Screener and Opioid Assessment for Patients with Pain-Revised, COMM Current Opioid Misuse Measure

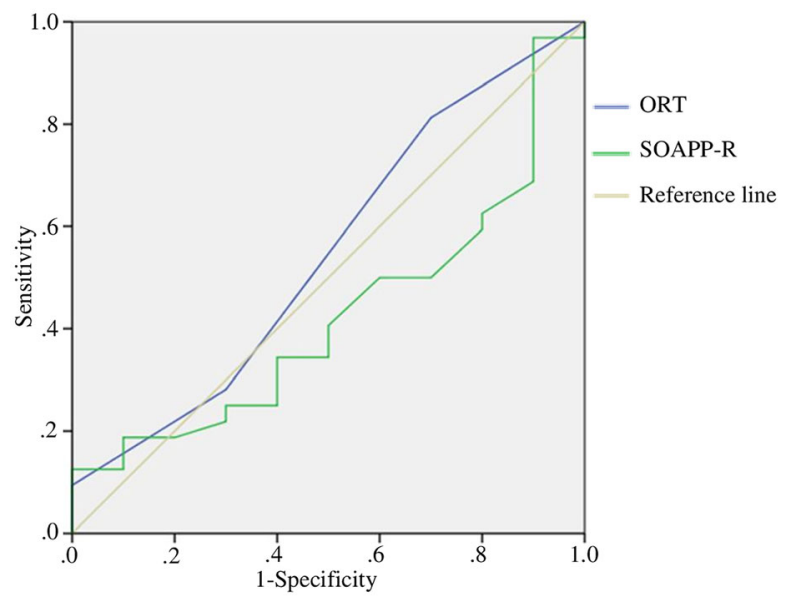

Fig. 3 Receiver operating characteristic curves comparing ORT (weighted score excluding item related to sexual abuse) and SOAPP-R to predict opioid abuse (criterion measure: DAST-10). $n=42$. ORT Opioid Risk Tool, $S O A P P-R$ Screener and Opioid Assessment for Patients with Pain-Revised, DAST-10 Drug Abuse Screening Test

prescriptions for opioids and benzodiazepines. These results agree with those of previous research showing that the simultaneous prescription of opioids and benzodiazepines is increasing, especially among patients receiving opioid treatment for more than 90 days [36]. This was the case for the participants in this study. This finding is particularly worrisome because previous research has shown that the risk of accidental death by overdose and cardiorespiratory problems increases when opioids and benzodiazepines are prescribed together $[1,7,37]$.

As measured with the SOAPP-R, the significant positive association found between pain intensity and the risk of opioid misuse was low to moderate $(0.24$, initial sample; 0.39 , followup sample). This finding agrees with those of previous research $[5,12]$ showing that people who report higher pain intensity may be at a higher risk of developing aberrant behavior in the use of prescribed opioids in an attempt to obtain analgesic effects.

In this study, a negative association was found between older age and the risk of misuse and abuse and abuse/misuse behavior: this relationship was of a higher magnitude in the initial sample. In fact, one of the items of the ORT includes being aged between 16 and 45 years as a risk factor. Although this is a frequent finding [38-42], a systematic review and meta-analysis concluded that further research should address this issue more deeply, given that most of the previous studies were shortterm ones and excluded persons with a history of substance abuse, which is a recognized risk factor for opioid abuse [43].

The correlational analyses showed moderate and moderate-to-high positive correlations between the ORT and the SOAPP-R in both samples, suggesting that although these tools are related, there is no overlap between them. Previous studies have not reported on correlations between the scores of both instruments.

The aim of the present study was to provide preliminary evidence of the diagnostic and predictive capacity of the Spanish translation of the ORT and the SOAPP-R in a sample of people with chronic pain. Values of the area under the curve and sensitivity, specificity, and predictive values showed that the discriminant capacity of the ORT was not acceptable in the diagnostic or 
Table 8 Sensitivity and specificity values of the total scores on the ORT (weighted scores excluding item related to sexual abuse) and the SOAPP-R for predicting opioid misuse (criterion COMM), $n=47$

\begin{tabular}{|c|c|c|c|}
\hline Instrument & $\begin{array}{l}\text { ORT/SOAPP-R } \\
\text { detection score is } \\
\text { positive if equal } \\
\text { to or greater than }\end{array}$ & Sensitivity & Specificity \\
\hline \multirow[t]{5}{*}{ ORT } & -1.0000 & 1.000 & 0.000 \\
\hline & 0.5000 & 0.821 & 0.286 \\
\hline & 1.5000 & 0.286 & 0.714 \\
\hline & 3.0000 & 0.107 & 1.000 \\
\hline & 5.0000 & 0.000 & 1.000 \\
\hline \multirow[t]{24}{*}{ SOAPP-R } & 14.0000 & 1.000 & 0.000 \\
\hline & 15.5000 & 0.964 & 0.000 \\
\hline & 17.0000 & 0.964 & 0.071 \\
\hline & 19.0000 & 0.929 & 0.143 \\
\hline & 21.5000 & 0.857 & 0.214 \\
\hline & 24.0000 & 0.821 & 0.214 \\
\hline & 25.5000 & 0.786 & 0.214 \\
\hline & 26.5000 & 0.750 & 0.286 \\
\hline & 27.5000 & 0.714 & 0.429 \\
\hline & 28.5000 & 0.714 & 0.500 \\
\hline & 29.5000 & 0.643 & 0.643 \\
\hline & 31.0000 & 0.607 & 0.643 \\
\hline & 32.5000 & 0.536 & 0.786 \\
\hline & 33.5000 & 0.500 & 0.857 \\
\hline & 35.0000 & 0.464 & 0.857 \\
\hline & 36.5000 & 0.429 & 0.857 \\
\hline & 37.5000 & 0.393 & 0.857 \\
\hline & 38.5000 & 0.393 & 0.929 \\
\hline & 39.5000 & 0.357 & 0.929 \\
\hline & 40.5000 & 0.321 & 0.929 \\
\hline & 41.5000 & 0.250 & 0.929 \\
\hline & 43.0000 & 0.250 & 1.000 \\
\hline & 44.5000 & 0.179 & 1.000 \\
\hline & 46.0000 & 0.143 & 1.000 \\
\hline
\end{tabular}

Table 8 continued

\begin{tabular}{clll}
\hline Instrument & $\begin{array}{l}\text { ORT/SOAPP-R } \\
\text { detection score is } \\
\text { positive if equal } \\
\text { to or greater than }\end{array}$ & Sensitivity & Specificity \\
\hline 47.5000 & 0.107 & 1.000 \\
48.5000 & 0.071 & 1.000 \\
50.5000 & 0.036 & 1.000 \\
53.0000 & 0.000 & 1.000 \\
\hline
\end{tabular}

ORT Opioid Risk Tool, SOAPP-R Screener and Opioid Assessment for Patients with Pain-Revised, COMM Current Opioid Misuse Measure

predictive study in relation to misuse and abuse. These findings agreed with those of previous studies showing that the diagnostic and predictive capacity of the ORT was not adequate [18-22]. It is also remarkable that, according to the analyses, a score of just 1 on the ORT (i.e., the presence of a single risk factor) was indicative of the patient being at risk of developing aberrant behavior when prescribed opioids.

Values of the area under the curve and sensitivity, specificity, and predictive values showed that, regarding misuse, the Spanish version of the SOAPP-R had high diagnostic efficiency and adequately classified $83 \%$ of the participants. Note that to determine the cutoff point, we prioritized sensitivity over specificity to reduce false negatives because of their risk to the patients' health and quality of life. These results agree with those of previous studies in which the SOAPP-R showed a sensitivity of 0.81 and a specificity of 0.68 for detecting aberrant medication-related behavior [14] and excellent discrimination between high- and low-risk patients $[44,45]$. Other studies have also shown that a high SOAPP-R score is associated with using multiple providers for controlled substance prescriptions [24] and with an increased likelihood of drug abuse [3].

Conversely, the capacity of the SOAPP-R to predict opioid misuse and abuse was limited because it only correctly classified $67 \%$ and $42 \%$ of the participants, respectively, in the followup study. The predictive capacity of the SOAPP$\mathrm{R}$ may be limited by the inclusion of items 
Table 9 Sensitivity and specificity values of the total scores on the ORT (weighted scores excluding item related to sexual abuse) and the SOAPP-R for predicting opioid abuse (criterion DAST-10), $n=47$

\begin{tabular}{|c|c|c|c|}
\hline Instrument & $\begin{array}{l}\text { ORT/SOAPP-R } \\
\text { detection score is } \\
\text { positive if equal } \\
\text { to or greater } \\
\text { than }\end{array}$ & Sensitivity & Specificity \\
\hline \multirow[t]{5}{*}{ ORT } & -1.0000 & 1.000 & 0.000 \\
\hline & 0.5000 & 0.813 & 0.300 \\
\hline & 1.5000 & 0.281 & 0.700 \\
\hline & 3.0000 & 0.094 & 1.000 \\
\hline & 5.0000 & 0.000 & 1.000 \\
\hline \multirow[t]{23}{*}{ SOAPP-R } & 14.0000 & 1.000 & 0.000 \\
\hline & 15.5000 & 0.969 & 0.000 \\
\hline & 17.0000 & 0.969 & 0.100 \\
\hline & 19.0000 & 0.906 & 0.100 \\
\hline & 21.5000 & 0.813 & 0.100 \\
\hline & 24.0000 & 0.781 & 0.100 \\
\hline & 25.5000 & 0.750 & 0.100 \\
\hline & 26.5000 & 0.688 & 0.100 \\
\hline & 27.5000 & 0.625 & 0.200 \\
\hline & 28.5000 & 0.594 & 0.200 \\
\hline & 29.5000 & 0.500 & 0.300 \\
\hline & 31.0000 & 0.500 & 0.400 \\
\hline & 32.5000 & 0.406 & 0.500 \\
\hline & 33.5000 & 0.344 & 0.500 \\
\hline & 35.0000 & 0.344 & 0.600 \\
\hline & 36.5000 & 0.313 & 0.600 \\
\hline & 37.5000 & 0.281 & 0.600 \\
\hline & 38.5000 & 0.250 & 0.600 \\
\hline & 39.5000 & 0.250 & 0.700 \\
\hline & 40.5000 & 0.219 & 0.700 \\
\hline & 41.5000 & 0.188 & 0.800 \\
\hline & 43.0000 & 0.188 & 0.900 \\
\hline & 44.5000 & 0.125 & 0.900 \\
\hline
\end{tabular}

Table 9 continued

\begin{tabular}{cccc}
\hline Instrument & $\begin{array}{l}\text { ORT/SOAPP-R } \\
\text { detection score is } \\
\text { positive if equal } \\
\text { to or greater } \\
\text { than }\end{array}$ & Sensitivity & Specificity \\
\hline 46.0000 & 0.125 & 1.000 \\
47.5000 & 0.094 & 1.000 \\
48.5000 & 0.063 & 1.000 \\
50.5000 & 0.031 & 1.000 \\
53.0000 & 0.000 & 1.000 \\
\hline
\end{tabular}

ORT Opioid Risk Tool, SOAPP-R Screener and Opioid Assessment for Patients with Pain-Revised, DAST-10 Drug Abuse Screening Test

reflecting problematic behavior that is not necessarily associated with opioid misuse or abuse, but which are associated with the condition of experiencing chronic pain. For example, the items related to mood swings, feeling bored, tension at home, or a difficult relationship with doctors are common issues in people with chronic pain.

The generalizability of the results of this study may be limited due to the sample sizes and the overrepresentation of women. Among the limitations of the present study, opioid misuse and abuse were measured using self-report instruments. Future research on the validity of the ORT and the SOAPP-R should use other methods. Another limitation is that the participants' responses to the two questionnaires may have been affected by social desirability bias [2, 21]. Although social desirability bias decreases when these two instruments are heteroadministered [21], as in the present study, future research should measure and control for its possible influence. The results may have also been influenced by the interaction of social desirability and the age of the participants, which have been shown to have a positive association [46-49]. In this study, the average age of the participants was around 60 years, which could be associated with higher social desirability. Future research is needed to investigate whether social desirability is a mediator of the relationship between age, self- 
reported risk factors, and opioid abuse or misuse.

Despite the preliminary nature of this study and the methodological limitations that may have biased the results, we suggest that clinicians should exercise caution when using the Spanish versions of the ORT and the SOAPP-R to help make decisions on opioid prescription. We need good-quality evidence on risk factors to develop accurate instruments for detecting people at risk of prescription opioid abuse and misuse [50]. Several recent models have postulated a reciprocal interaction between the psychological factors that contribute to the development of substance abuse and the psychological factors that contribute to adaptation to chronic pain [51, 52]. Future research could include these risk factors in instruments such as the ORT and SOAPP-R in order to improve their capacity to detect this type of misuse and abuse in such patients. The detection and prevention of opioid misuse and abuse is and will always be an essential part of good health care [53-55]. On the basis of social equality, this type of intervention must be made available to Hispanic/ Latino communities wherever they form underserved minority populations. The adaptation of assessment instruments into Spanish would represent a step forward in this direction [56].

\section{CONCLUSION}

Further research is needed on the diagnostic and predictive capacity of the Spanish versions of Opioid Risk Tool and the Screener and Opioid Assessment for Patients with Pain-Revised. When using these instruments to make decisions on opioid administration, clinicians should rely on additional information on the psychological factors that contribute to adaptation to chronic pain.

\section{ACKNOWLEDGEMENTS}

The authors acknowledge the invaluable contribution of the participants of this study and thank them for their generosity.
Funding. This work was supported by the Spanish Ministry of Science and Innovation (PID2019-106086RB-I00), and the Regional Government of Andalusia (HUM-566 and UMA20-FEDERJA-118). Rocío de la Vega's work was supported by the Spanish Ministry of Science and Innovation with a Ramon y Cajal contract (RYC2018-024722-I). Funding for the journal's Rapid Service Fee: Universidad de Málaga/CBUA.

Authorship. All the authors meet the International Committee of Medical Journal Editors (ICMJE) criteria for authorship for this article, take responsibility for the integrity of the work as a whole, and have given their approval for this version to be published.

Author Contributions. All authors contributed to the study conception and design. Material preparation, data collection and analysis were performed by CR-M, AEL-M, RE, ÁR-P, AG-E and RF-B. The first draft of the manuscript was written by RE and all authors commented on previous versions of the manuscript. All authors read and approved the final manuscript.

Disclosures. Rosa Esteve, Ángela ReyesPérez, Carmen Ramírez-Maestre, Andrea Gutiérrez-Extremera, Rocío Fuentes-Bravo, Rocío de la Vega, Gema T. Ruíz-Párraga, Elena R. Serrano-Ibáñez, and Alicia E. López-Martínez declare that they have no conflicts of interest.

Compliance with Ethics Guidelines. All the procedures were conducted in accordance with the Helsinki Declaration of 1964 and its later amendments. The project of which this study is part received ethical clearance by the Institutional Ethics Review Board (Reference: CEUMA 66-2019-H). Participants provided signed informed consent and confidentiality was maintained at every stage of the study.

Data Availability. The datasets generated during and analyzed during the current study are available in the Mendeley Data repository: https://data.mendeley.com/datasets/ 38btcyg3nr/1. 
Open Access. This article is licensed under a Creative Commons Attribution-NonCommercial 4.0 International License, which permits any non-commercial use, sharing, adaptation, distribution and reproduction in any medium or format, as long as you give appropriate credit to the original author(s) and the source, provide a link to the Creative Commons licence, and indicate if changes were made. The images or other third party material in this article are included in the article's Creative Commons licence, unless indicated otherwise in a credit line to the material. If material is not included in the article's Creative Commons licence and your intended use is not permitted by statutory regulation or exceeds the permitted use, you will need to obtain permission directly from the copyright holder. To view a copy of this licence, visit http://creativecommons.org/licenses/by$\mathrm{nc} / 4.0 /$.

\section{REFERENCES}

1. International Narcotics Control Board. Report 2016 (E/INCB/2016/1). New York: United Nations; 2017. https://www.incb.org/documents/Publications/ AnnualReports/AR2016/English/AR2016_E_ebook. pdf. Accessed 27 Sep 2021.

2. Els C, Jackson TD, Kunyk D, Lappi VG, Sonnenberg B, Hagtvedt R, Sharma S, Kolahdooz F, Straube S. Adverse events associated with medium-and longterm use of opioids for chronic non-cancer pain: an overview of Cochrane Reviews. Cochrane Database Syst Rev. 2017. https://doi.org/10.1002/14651858. CD012509.pub2.

3. Chou R, Fanciullo GJ, Fine PG, Miaskowski C, Passik SD, Portenoy RK. Opioids for chronic pain: prediction and identification of aberrant drug-related behaviors: a review of the evidence for an American Pain Society and American Academy of Pain Medicine clinical practice guideline. J Pain. 2009;10: 131-46.

4. Højsted J, Sjøgren P. Addiction to opioids in chronic pain patients: a literature review. Eur J Pain. 2007;11:490-518.

5. Kaye AD, Jones MR, Kaye AM, Ripoll JG, Jones DE, Galan V, Beakley BD, Calixto F, Bolden JL, Urman $\mathrm{RD}$, Manchikanti L. Prescription opioid abuse in chronic pain: an updated review of opioid abuse predictors and strategies to curb opioid abuse: part 2. Pain Physician. 2017;20:S111-E133.

6. Volkow ND, McLellan AT. Opioid abuse in chronic pain-misconceptions and mitigation strategies. N Engl J Med. 2016;374:1253-63.

7. Ray WA, Chung CP, Murray KT, Hall K, Stein CM. Prescription of long-acting opioids and mortality in patients with chronic pain. JAMA. 2016;315: 2415-23.

8. Shipton EE, Shipton AJ, Williman JA, Shipton EA. Deaths from opioid overdosing: implications of coroners' inquest reports 2008-2012 and annual rise in opioid prescription rates: a population-based cohort study. Pain Ther. 2017;6:203-15.

9. Substance Abuse and Mental Health Services Administration. The opioid crisis and the Hispanic/ Latino population: an urgent issue. Publ. no. PEP2005-02-002. Rockville, MD: Substance Abuse and Mental Health Services Administration; 2020. https://store.samhsa.gov/sites/default/files/ SAMHSA_Digital_Download/PEP20-05-02-002.pdf. Accessed 27 Sep 2021.

10. Anderson KO, Green CR, Payne R. Racial and ethnic disparities in pain: causes and consequences of unequal care. J Pain. 2009;10:1187-204.

11. Morales ME, Yong RJ. Racial and ethnic disparities in the treatment of chronic pain. Pain Med. 2021;22:75-90.

12. Sehgal N, Manchikanti L, Smith HS. Prescription opioid abuse in chronic pain: a review of opioid abuse predictors and strategies to curb opioid abuse. Pain Physician. 2012;15:ES67-92.

13. Webster LR, Webster RM. Predicting aberrant behaviors in opioid-treated patients: preliminary validation of the opioid risk tool. Pain Med. 2005;6: 432-42.

14. Butler SF, Fernandez K, Benoit C, Budman SH, Jamison RN. Validation of the revised screener and opioid assessment for patients with pain. J Pain. 2008;9:360-72.

15. Butler SF, Zacharoff KL, Budman SH, Jamison RN, Black R, Dawsey R, Ondarza A. Spanish translation and linguistic validation of the Screener and Opioid Assessment for Patients with Pain-Revised (SOAPP-R). Pain Med. 2013;14:1032-8.

16. Alzeer AH, Jones J, Bair MJ. Review of factors, methods, and outcome definition in designing opioid abuse predictive models. Pain Med. 2018;19: 997-1009. 
17. Cheatle MD, Compton PA, Dhingra L, Wasser TE, O'Brien CP. Development of the revised opioid risk tool to predict opioid use disorder in patients with chronic nonmalignant pain. J Pain. 2019;20: 842-51.

18. Jones T, Moore T, Levy JL, Daffron S, Browder JH, Allen L, Passik SD. A comparison of various risk screening methods in predicting discharge from opioid treatment. Clin J Pain. 2012;28:93-100.

19. Jones T, Lookatch S, Moore T. Validation of a new risk assessment tool: the Brief Risk Questionnaire. J Opioid Manage. 2015;11:171-83.

20. Jones T, Moore T. Preliminary data on a new opioid risk assessment measure: the brief risk interview. J Opioid Manage. 2013;9:19-27.

21. Jones T, Passik SD. A comparison of methods of administering the opioid risk tool. J Opioid Manage. $2011 ; 7: 347-51$.

22. Moore TM, Jones T, Browder JH, Daffron S, Passik SD. A comparison of common screening methods for predicting aberrant drug-related behavior among patients receiving opioids for chronic pain management. Pain Med. 2009;10:1426-33.

23. Butler SF, Budman SH, Fernández K, Jamison RN. Validation of a screener and opioid assessment measure for patients with chronic pain. Pain. 2004;2004(112):65-75.

24. Weiner SG, Horton LC, Green TC, Butler SF. A comparison of an opioid abuse screening tool and prescription drug monitoring data in the emergency department. Drug Alcohol Depend. 2016;159:152-7.

25. Butler SF, Budman SH, Fernández KC, Houle B, Benoit C, Katz N, Jamison RN. Development and validation of the current opioid misuse measure. Pain. 2007;130:144-56.

26. Skinner HA. The drug abuse screening test. Addict Behav. 1982;7:363-71.

27. Pérez B, García LG, De Vicente MP, Oliveras MA, Lahoz M. Validación española del drug abuse screening test (DAST-20 y DAST-10) [Spanish validation of the Drug Abuse Sreening Test (DAS-20 and DAST-10]. Salud Drogas. 2010;10:35-50.

28. Chou R, Turner JA, Devine EB, Hansen RN, Sullivan SD, Blazina I, Dana T, Bougatsos C, Deyo RA. The effectiveness and risks of long-term opioid therapy for chronic pain: a systematic review for a National Institute of Health Pathways to Prevention Workshop. Ann Intern Med. 2015;162:276-86.
29. Dowell D, Haegerich TM, Chou R. CDC guideline for prescribing opioids for chronic pain-United States, 2016. JAMA. 2016;315:1624-45.

30. Jensen MP, Karoly P. Self-report scales and procedures for assessing pain in adults. In: Turk DC, Melzack R, editors. Handbook of pain assessment. New York: Guilford Press; 2011. p. 19-44.

31. Butler S, Budman S, Fanciullo G, Jamison R. Cross validation of the Current Opioid Misuse Measure (COMM) to monitor chronic pain patients on opioid therapy. Clin J Pain. 2010;26:770-6.

32. Reyes-Pérez A, López-Martínez AE, Esteve R, Ramírez-Maestre C. Spanish validation of the COMM scale to assess the misuse of prescription opioids in patients with chronic pain. Int J Ment Health Addict 2021 (under review)

33. Cohen J. Statistical power analysis for the behavioral sciences. 2nd ed. Hillsdale: Lawrence Erlbaum Associates Inc; 1988.

34. Metz CE. Basic principles of ROC analysis. Semin Nucl Med. 1978;8:283-98.

35. Zweig MH, Campbell G. Receiver-operating characteristic (ROC) plots: a fundamental evaluation tool in clinical medicine. Clin Chem. 1993;39: 561-77.

36. Hwang CS, Kang EM, Kornegay CJ, Staffa JA, Jones CM, McAninch JK. Trends in the concomitant prescribing of opioids and benzodiazepines, 2002-2014. Am J Prev Med. 2016;51:151-60.

37. Horsfall JT, Sprague JE. The pharmacology and toxicology of the 'Holy Trinity.' Basic Clin Pharmacol Toxicol. 2017;120:115-9.

38. Edlund MJ, Steffick D, Hudson T, Harris KM, Sullivan M. Risk factors for clinically recognized opioid abuse and dependence among veterans using opioids for chronic noncancer pain. Pain. 2007;129: 355-62.

39. Ives TJ, Chelminski PR, Hammett-Stabler CA, Malone RM, Perhac JS, Potisek NM, Shilliday BB, DeWalt DA, Pignone MP. Predictors of opioid misuse in patients with chronic pain: a prospective cohort study. BMC Health Serv Res. 2006;6:1-10.

40. Reid MC, Engles-Horton LL, Weber MB, Kerns RD, Rogers EL, O'Connor PG. Use of opioid medications for chronic pain syndromes in primary care. J Gen Intern Med. 2002;17:173-9.

41. Kerridge BT, Saha TD, Chou P, Zhang H, Jung J, Ruan J, Smith SM, Huang B, Hasin DS. Gender and nonmedical prescription opioid use and DSM-5 nonmedical prescription opioid use disorder: results 
from the National Epidemiologic Survey on Alcohol and Related Conditions-III. Drug Alcohol Depend. $2015 ; 156: 47-56$.

42. Cragg A, Hau JP, Woo SA, Kitchen SA, Liu C, DoyleWaters MM, Hohl CM. Risk factors for misuse of prescribed opioids: a systematic review and metaanalysis. Ann Emerg Med. 2019;74:634-46.

43. Papaleontiou M, Henderson CR, Turner BJ, Moore AA, Olkhovskaya Y, Amanfo L, Reid MC. Outcomes associated with opioid use in the treatment of chronic pain in older adults: a systematic review and meta-analysis. J Am Geriatr Soc. 2010;58: 1353-69.

44. Butler SF, Budman SH, Fernandez KC, Fanciullo GJ, Jamison RN. Cross-validation of a screener to predict opioid misuse in chronic pain patients (SOAPPR). J Addict Med. 2009;3:66-73.

45. Passik SD, Narayana A, Yang R. Aberrant drug-related behavior observed during a 12-week open-label extension period of a study involving patients taking chronic opioid therapy for persistent pain and fentanyl buccal tablet or traditional short-acting opioid for breakthrough pain. Pain Med. 2014;15:365-1372.

46. Carstensen L, Cone JD. Social desirability and the measurement of psychological well-being in elderly persons. J Gerontol. 1983;38:713-5.

47. Dijkstra J, Smit H, Comijs HC. Using social desirability scales in research among elderly. Qual Quant. 2001;35:107-15.

48. Nuevo R, Montorio I, Márquez-González M, Cabrera I, Izal M, Pérez-Rojo G. Diferencias asociadas a la edad en el efecto de la deseabilidad social en el autoinforme del estado emocional [Age-related differences in the effect of social desirability on self- reported emotional state]. Rev Esp Geriatr Gerontol. $2009 ; 44: 85-9$.

49. Ray JJ. Lie scales and the elderly. Pers Individ Dif. 1988;9:417-8.

50. Voon P, Karamouzian M, Kerr T. Chronic pain and opioid misuse: a review of reviews. Subst Abuse Treat Prev Policy. 2017;12:1-9.

51. Ditre JW, Zale EL, LaRowe LR. A reciprocal model of pain and substance use: transdiagnostic considerations, clinical implications, and future directions. Ann Rev Clin Psychol. 2019;15:503-28.

52. Garland EL. Psychosocial intervention and the reward system in pain and opioid misuse: new opportunities and directions. Pain. 2020;161: 2659-66.

53. Kraus M, Lintzeris N, Maier C, Savage S. Recommendations for the prevention, detection, treatment and management of prescription opioid analgesic dependence: outcomes from the Opioid Analgesic Dependence Education Nexus (OPEN) meeting. Int J Ment Health Addict. 2016;14:313-21.

54. Manchikanti L, Singh V, Kaye AD, Hirsch JA. Lessons for better pain management in the future: learning from the past. Pain Ther. 2020;9:373-91.

55. Shipton EA, Shipton EE, Shipton AJ. A review of the opioid epidemic: what do we do about it? Pain Ther. 2018;7:23-36.

56. Cross-Divisional Task Force on Clinical Responses to the Opioid Crisis. Cultural competency in assessing and treating opioid use disorder. American Psychological Association. https://www.apa. org/advocacy/substance-use/opioids/resources/ cultural-competency.pdf. Accessed 27 Sep 2021. 